\title{
22. CONTACT METAMORPHISM OF KEROGEN IN SEDIMENTS FROM LEG 41: CAPE VERDE RISE AND BASIN
}

\author{
Wallace G. Dow, ${ }^{1}$ The Superior Oil Company, Houston, Texas
}

\section{INTRODUCTION}

Six samples from Leg 41 of the Deep Sea Drilling Project were acquired for the purpose of studying the contact metamorphic effects of an igneous intrusion on organic-rich Upper Cretaceous shales (Baker et al., this volume). These samples provide an opportunity to investigate the petroleum convertibility of kerogen from the Cretaceous black shale which has been encountered in a number of North Atlantic DSDP sites. Oil-generating organic matter is common in many of the black shale samples, but always at maturities insufficient for hydrocarbon generation.

One sample represents Upper Cretaceous black shale in an immature state from Site 367 in the Cape Verde Basin and is analyzed for control purposes. The remaining five samples are from the Upper Cretaceous black shale sequence at various distances immediately below a diabase sill at Site 368 on the Cape Verde Rise (Figure 1).

\section{EXPERIMENTAL}

The samples were oven dried at $40^{\circ} \mathrm{C}$ overnight and then freeze dried for $8 \mathrm{hr}$. A portion of the sample was taken for carbonate and organic carbon analysis. This sample was pulverized and passed through a 60 -mesh sieve. One-half gram was reacted with $20 \% \mathrm{HCl}$ for 16 $\mathrm{hr}$ to remove carbonates. The residue was analyzed for carbon in a LECO WR12 carbon determinator. The remainder of the sample was ground and soxhlet extracted with benzene-methanol (azeotrope composition 3:2) for $20 \mathrm{hr}$. The residue was pulverized and extracted again for $40 \mathrm{hr}$. In both extractions, copper was added to the boiling flask to remove sulfur. The extracts were combined, the solvent evaporated, and the extracts weighed.

The extracts were separated by liquid chromatography. Asphaltenes were precipitated by the addition of hexane and removed by filtration through a column packed with powdered teflon. The soluble fraction was further separated on a column containing $21.3 \mathrm{~g}$ Merck \#60 silica gel and $7.1 \mathrm{~g} \mathrm{Alcoa} \mathrm{F-20} \mathrm{alumina.} \mathrm{Elution}$ with hexane, benzene, and benzene-methanol yielded the saturate, aromatic, and NSO fractions, respectively. Asphaltenes were eluted from the teflon column with benzene-methanol and after solvent evaporation, washed with distilled water. All fractions were dried and weighed. The saturate fraction was analyzed by gas chromatography on a Varian 1400 equipped with a 6.1meter eutectic column programmed from $160^{\circ} \mathrm{C}$ to $350^{\circ} \mathrm{C}$ at $20^{\circ} / \mathrm{min}$.

\footnotetext{
'Present address: Getty Oil Company, 3903 Stoney Brooke, Houston, Texas 77063 .
}

The extracted sample $(35 \mathrm{~g})$ was treated with $\mathrm{HCl}$ (20\%) and $\mathrm{HF}(70 \%)$ to concentrate the kerogen fraction. The residue was thoroughly washed with distilled water, freeze dried for $16 \mathrm{hr}$ to remove all traces of moisture, mixed with epoxy to form a plug, and polished. Thermal maturity was determined by standard vitrinite reflectance analysis (Stach, 1975) with a Zeiss Universal reflecting microscope. Kerogen type was also determined in reflected light by visual examination.

\section{RESULTS}

Dark gray Cretaceous shales from Sites 367 and 368 are generally high in organic carbon and amorphous, oil-generating organic matter, but the percentages of both vary considerably. The Cretaceous shales have not undergone sufficient burial maturation for oil generation to occur but there is, however, a marked contact metamorphic effect on the Site 368 samples in the immediate proximity of a diabase sill. Systematic changes in vitrinite reflectivity, percent saturates in the organic extract, and carbon preference index of the $n_{\text {- }}$ alkanes attests to the thermal effects of contact metamorphism. One sample 2.67 meters below the sill, contains an anomalously high relative amount of oillike organic extract, attesting to the oil-generating capability of the invaded sediments. Samples from within 2 meters of the sill exhibit characteristics typical of severe heating and the effect of the sill is considerably less but still apparent 8.39 meters below the contact. These data confirm that organic-rich Cretaceous shales which are high in amorphous organic matter could be effective oil source rocks if subjected to sufficient thermal maturation. The bulk quantity of hydrocarbons (oil and gas) associated with igneous activity are probably insignificant in terms of possible commercial reserves.

\section{DISCUSSION}

\section{Organic Richness and Kerogen Type}

Organic carbon in most of the analyzed samples is quite high, and on this basis they are rated as good to very good in source quality. One sample in immediate proximity to the diabase sill is substantially lower in organic carbon than the rest, but this may be due to pyrolysis of some of the kerogen by the heat of the intrusion. The variation in organic carbon in the other samples (Table 1) may be related more to depositional variations than to contact metamorphic effects.

Amorphous, oil-generating organic matter predominates in all of the samples, but there is also sufficient plant debris to provide reliable maturity measurements. The sample from Site 367 contains the 

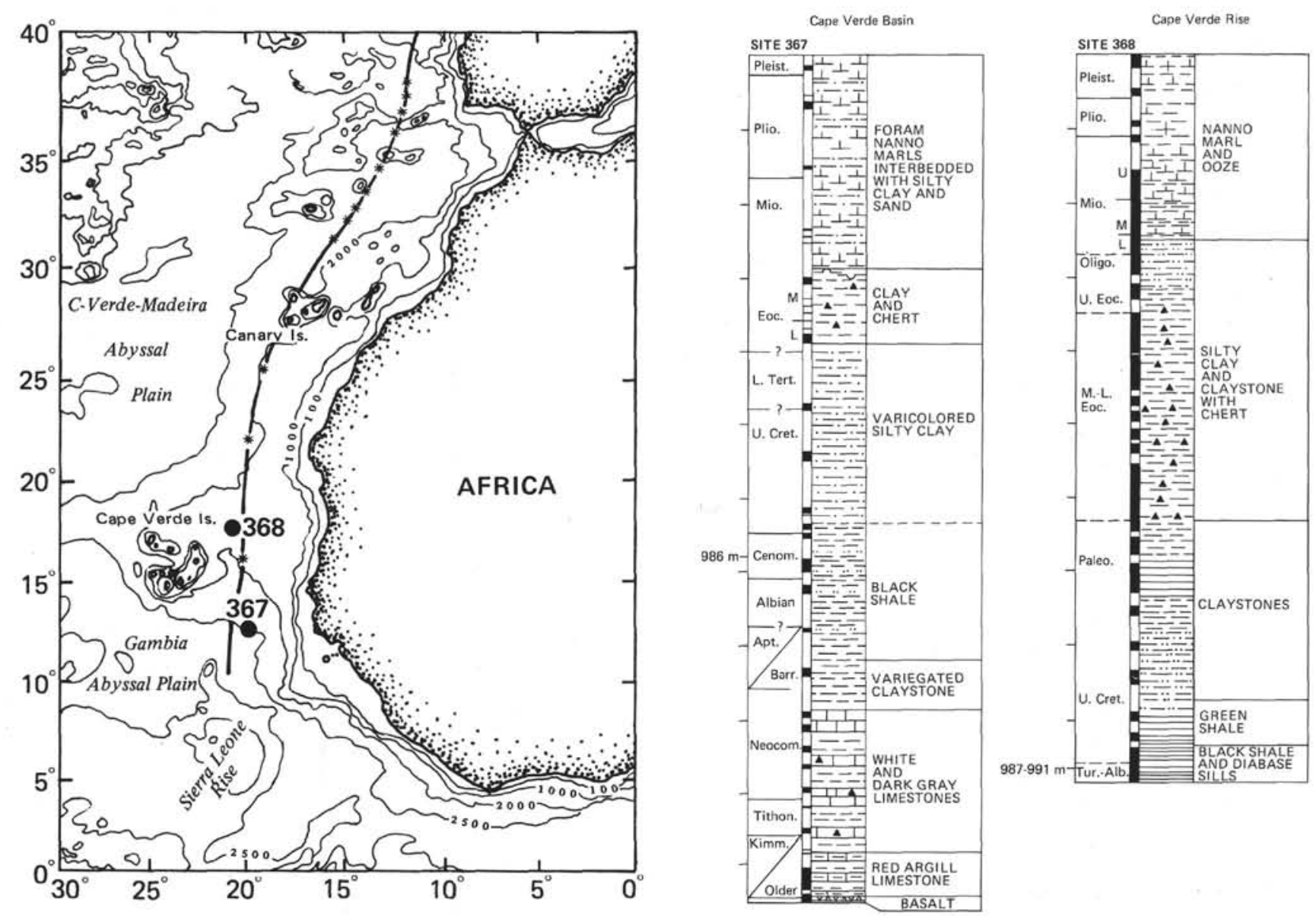

Figure 1. Site location map and columnar sections for Sites 367 and 368.

TABLE 1

Kerogen Data

\begin{tabular}{lcccl}
\hline $\begin{array}{c}\text { Sample } \\
\text { (Interval } \\
\text { in cm) }\end{array}$ & $\begin{array}{c}\text { Distance } \\
\text { Below } \\
\text { Sill }\end{array}$ & $\begin{array}{c}\text { HC1 } \\
\text { Insol. } \\
\text { (wt \%) }\end{array}$ & $\begin{array}{c}\text { Org. Carb. } \\
\text { (wt \%) }\end{array}$ & $\begin{array}{c}\text { Source } \\
\text { Quality } \\
\text { Rating }\end{array}$ \\
\hline $\begin{array}{l}367-19-4, \\
5-10\end{array}$ & N/A & 69.3 & 7.75 & Very good \\
$\begin{array}{l}368-62-3, \\
70-80\end{array}$ & $0.71 \mathrm{~m}$ & 83.9 & 0.53 & Marginal \\
$\begin{array}{l}368-62-4, \\
44-52\end{array}$ & $1.93 \mathrm{~m}$ & 85.1 & 6.63 & Very good \\
$\begin{array}{l}368-62-4, \\
118-126\end{array}$ & $2.67 \mathrm{~m}$ & 96.7 & 1.93 & Very good \\
$\begin{array}{l}368-63-3, \\
141-144\end{array}$ & $7.41 \mathrm{~m}$ & 98.0 & 1.38 & Good \\
$\begin{array}{l}368-63-4, \\
90-98\end{array}$ & $8.39 \mathrm{~m}$ & 97.0 & 3.43 & Very good \\
\hline
\end{tabular}

lowest relative percent of amorphous kerogen in all of the samples. The Cretaceous shales are good to very good quality source beds capable of generating primarily liquid hydrocarbons and wet hydrocarbon gases.

\section{Organic Extract}

Tables 2 and 3 summarize organic extract data, and gas chromatograms of the saturate fraction are shown on Figure 2. The sample from Site 367 has a low
TABLE 2

Soxhlet Extraction Data

\begin{tabular}{lrrrrr}
\hline $\begin{array}{l}\text { Sample } \\
\text { (Interval } \\
\text { in cm) }\end{array}$ & $\begin{array}{c}\text { Total } \\
\text { Extract } \\
\text { (ppm) }\end{array}$ & \multicolumn{5}{c}{ Percent Composition } \\
\hline $\begin{array}{l}367-19-4, \\
5-10\end{array}$ & 5,080 & 54.5 & 9.0 & 10.2 & 26.3 \\
$\begin{array}{l}368-62-3, \\
70-80\end{array}$ & 420 & 14.4 & 44.1 & 12.7 & 28.8 \\
$\begin{array}{l}368-62-4, \\
44-52\end{array}$ & 4,490 & 5.5 & 46.4 & 27.7 & 20.4 \\
$\begin{array}{l}368-62-4, \\
118-126\end{array}$ & 4,930 & 7.6 & 41.9 & 22.0 & 28.5 \\
$\begin{array}{l}368-63-3, \\
\begin{array}{l}141-144 \\
368-63-4,\end{array}\end{array}$ & 1,120 & 15.2 & 26.4 & 22.4 & 36.0 \\
$90-98$ & 3,560 & 25.7 & 16.6 & 21.1 & 36.5 \\
\hline
\end{tabular}

extract/organic carbon ratio, a high percentage of asphaltenes, and a low percentage of saturates. Normal alkanes are not abundant, and their distribution is characteristic of a thermally immature kerogen. The sample from Site 368, 8.39 meters below the diabase sill, is very similar but shows some thermal effects, especially in the relative amounts of saturates and asphaltenes. The remaining samples exhibit a systematic decrease in asphaltenes, increase in saturates, and decrease in carbon preference index as 

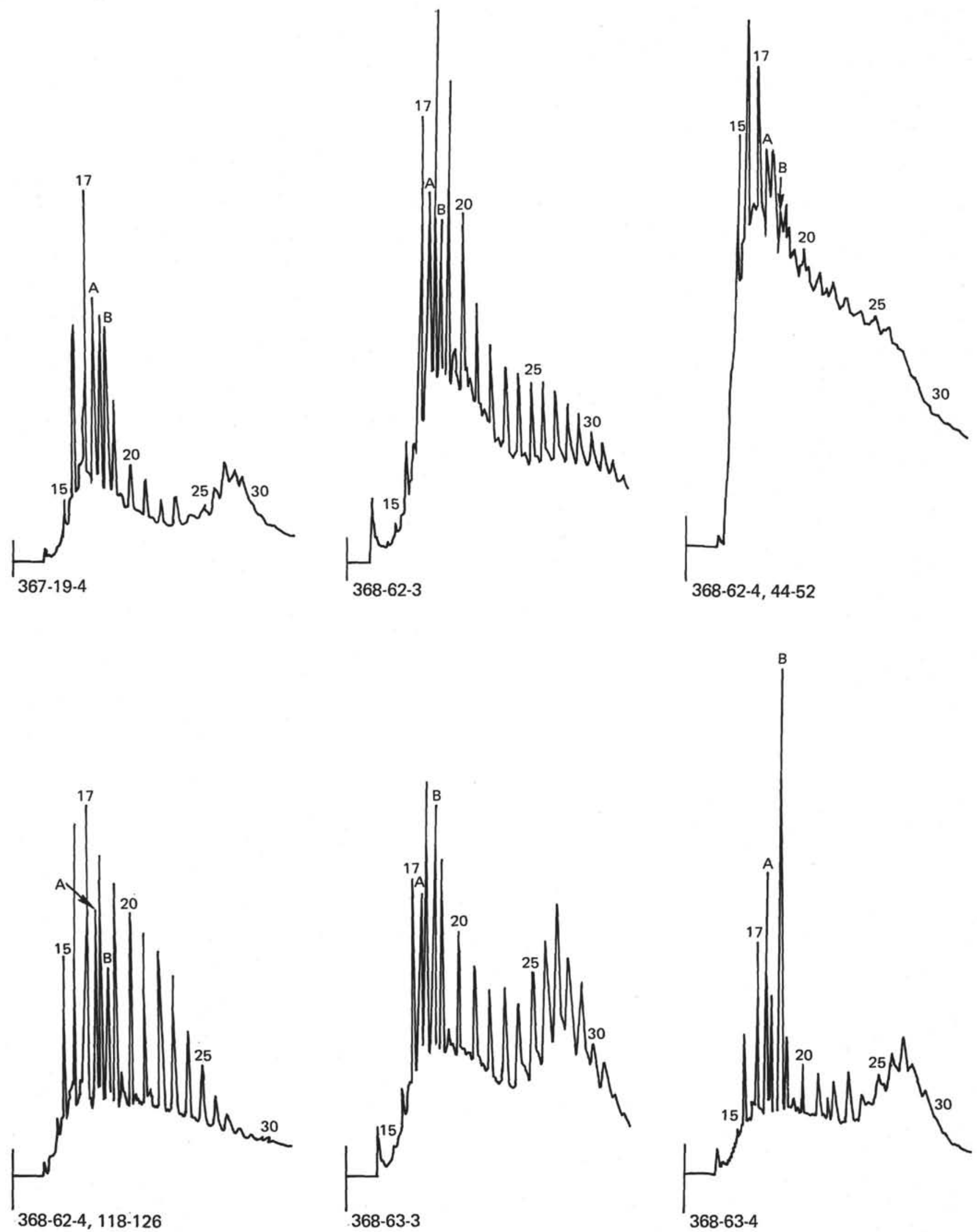

Figure 2. Gas chromatograms of saturate fraction analyzed with Varian 1400 equipped with a 6.1 meter eutectic column programmed from $160^{\circ} \mathrm{C}$ to $350^{\circ} \mathrm{C}$ at $20^{\circ} / \mathrm{min}$. A is pristane, $B$ is phytane. 
TABLE 3

Summary Data

\begin{tabular}{llccc}
\hline $\begin{array}{c}\text { Sample } \\
\text { (Interval } \\
\text { in cm) }\end{array}$ & $\begin{array}{c}\text { Dominant and } \\
\text { Secondary } \\
\text { Kerogen Types }\end{array}$ & $\begin{array}{c}\text { Extract } \\
\text { CPI }\end{array}$ & $\begin{array}{c}\text { Extract/ } \\
\text { Org. } \\
\text { Carb. }\end{array}$ & $R_{O}(\%)$ \\
\hline $\begin{array}{l}367-19-4, \\
5-10\end{array}$ & Amorphous/Humic & 1.32 & 0.066 & 0.24 \\
$\begin{array}{l}368-62-3, \\
70-80\end{array}$ & Amorphous/Liptinitic & 1.05 & 0.079 & - \\
$\begin{array}{l}368-62-4, \\
44-52\end{array}$ & Amorphous/Humic & 1.15 & 0.068 & 2.60 \\
$\begin{array}{l}368-62-4, \\
118-126\end{array}$ & Amorphous/Liptinitic & 1.28 & 0.255 & 1.44 \\
$368-63-3$, & Amorphous/Liptinitic & 1.29 & 0.081 & 1.05 \\
$\begin{array}{l}141-144 \\
368-63-4,\end{array}$ & Amorphous/Liptinitic & 1.36 & 0.104 & 0.85 \\
$90-98$ & & & & \\
\hline
\end{tabular}

the sill is approached. The sample from 2.67 meters below the sill contact contains an $n$-alkane distribution very similar to a mature crude oil (Figure 2), but two samples closer to the sill exhibit very unusual and unexplained gas chromatograms. The absence of $n$ alkanes in one sample suggests biodegradation, perhaps since the samples were collected.

The oil-like organic extracts in three samples are the product of contact metamorphism associated with the superjacent diabase sill. This may be considered evidence that the kerogen in these shales is convertible to crude oil as also indicated by their visual kerogen characteristics. It is evident that the effects of the intrusion only slightly alter the organic extract characteristics at a distance of 8.39 meters below the contact.

\section{Kerogen Maturation}

The samples from Site 367 have an average $R_{o}$ of 0.24 (Table 3 ) which is equivalent to peat or very low grade lignite. This sample has undergone only minimal thermal maturation, a conclusion that is also indicated by the nature of its organic extract.

Five samples from Site 368 reflect the effect of contact metamorphism associated with the overlying diabase sill. Two samples within 2 meters of the sill contact contain abundant natural coke and one did not have sufficient uncoked vitrinite for analysis. Because of its finely microcrystalline structure, coke cannot be used to measure maturity by reflection techniques. The other four samples systematically decline in reflectivity below the sill (Table 3, Figure 3), but all have experienced some contact metamorphism. Relatively thin igneous bodies usually affect organic matter in invaded sediments to a distance roughly equivalent to their thickness which, in this case, is about 13 meters (Bostick, 1970). The most remote sample analyzed is only 8.39 meters below the sill.

\section{CONCLUSIONS}

The greatest concentration of oil-like organic extract is found in the sample from 2.67 meters below the sill. The average $R_{o}$ of this sample is 1.44 . The sample 8.39 meters below the sill had an average $R_{o}$ of 0.85 , but contained organic extract which closely resembled the extract in the unaltered sample from Site 367. These

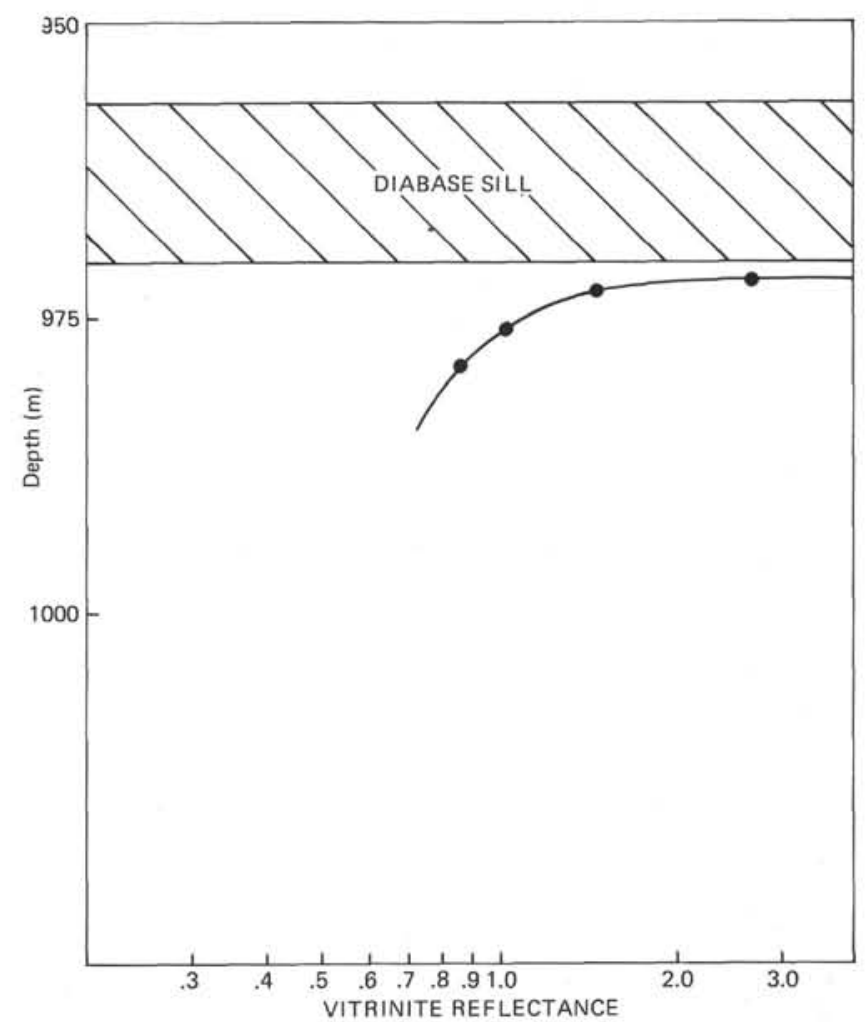

Figure 3. Kerogen maturation profile for Site 368.

observations seem uncompatible in terms of normal burial catagenesis (Dow, 1977), and suggest that vitrinite reflectance is more sensitive than organic extract to conditions of very rapid heating and cooling. Apparently migration of generated liquid petroleum out of a rock system is more time dependent than the chemical changes which affect the reflectivity of coal macerals.

The results of this work indicate that potential oil source rocks exist in the Cretaceous black shale sequence along the northwestern coast of Africa. The section is thermally immature, however, and would have to be buried to considerably greater depths before petroleum could be generated and expelled. Intense heating in immediate proximity to a thin igneous intrusion has confirmed that kerogen in the section has the capacity to generate petroleum liquids, but the effects are very local and the quantities formed are quantitatively insignificant.

\section{ACKNOWLEDGMENTS}

Appreciation is expressed to The Superior Oil Company for underwriting the analytical work and to Dr. E.W. Baker for supplying the sample material.

\section{REFERENCES}

Bostick, N.H., 1970. Thermal alteration of clastic organic particles (phytoclasts) as an indicator of contact and burial metamorphism in sedimentary rocks: Ph.D. Dissertation, Stanford University, Palo Alto, California, 220 p.

Dow, W.G., 1977. Kerogen studies and geological interpretations: J. Geochem. Explor. v. 7, no. 2.

Stach, E., 1975. Coal petrology: Berlin (Gebrüder Borntraeger). 